\title{
Mean value of B-mode optic nerve sheath diameter as an indicator of increased intracranial pressure: a systematic review and meta-analysis
}

Lisandro Montorfano', Qian Yu', Stephen J. Bordes ${ }^{1}$, Shankarapryan Sivanushanthan², Raul J. Rosenthal ${ }^{1}$ and Miguel Montorfano ${ }^{3^{*}}$ (D)

\begin{abstract}
Objectives: Timely diagnosis and treatment of increased intracranial pressure can decrease morbidity and prevent mortality. The present meta-analysis aims to determine the mean value of the ONSD measured in patients with various elevated ICP etiologies under different clinical settings, as well as comparing the value of ONSD between patients with and without elevated ICP.

Methods: This meta-analysis complied with the Preferred Reporting Items for Systematic Reviews and Meta-analysis Statement8. PubMed, Embase, and Cochrane Library were searched to identify ONSD measured by US for patients with increased ICP from establishment to October 2020.

Results: A total of 779 patients with elevated ICP among 22 studies were included in the present meta-analysis. Studies were published between 2003 and 2020. Eighteen were comparative (18/22, 81.8\%), and four were single-armed study (4/22, 18.2\%). Twenty were prospective studies (20/22, 90.9\%). There was moderate-to-high heterogeneity based on the prediction ellipse area and variance logit of sensitivity and specificity.

Conclusions: The mean value of the ONSD among patients diagnosed with increased ICP was $5.82 \mathrm{~mm}(95 \% \mathrm{Cl}$ 5.58-6.06 mm). Variations were observed based on etiology of intracranial hypertension, clinical settings where ONSD was measured, and standards for diagnosing intracranial hypertension. The US-ONSD among patient with elevated ICP was significantly higher than the normal control. Although a cut-off value is not clearly determined, these mean values can be implemented to evaluate the sensitivity and specificity of US-ONSD in diagnosing intracranial hypertension in future studies.
\end{abstract}

Keywords: Trauma, traumatic brain injury, ocular ultrasound, Intracranial pressure, Optic nerve sheath, Optic nerve sheath diameter, Point-of-care ultrasound

*Correspondence: miguel.montorfano@winfocus.org

${ }^{3}$ Department of Ultrasound and Vascular Doppler, Hospital de Emergencias "Dr. Clemente Alvarez", Av. Pellegrini 3205, Rosario, Santa Fe, Argentina

Full list of author information is available at the end of the article

\section{Introduction}

Increased intracranial pressure (ICP) can arise from a variety of cerebral conditions such as stroke, bleeding, malignancy, and trauma [1]. Timely diagnosis and treatment of elevated ICP could prevent detrimental consequences such herniation and decrease mortality [2, 3]. Although invasive intracranial monitoring has been regarded the "gold-standard", it demands neurosurgical 
expertise and is associated with post-procedural complications including infection, hemorrhage, and misplacement [4]. Signs of elevated ICP could manifest as effacement of ventricles and midline shift on CT and MRI [5], but these imaging modalities are not always available in all medical environment and require time for transfer. Within the last two decades, evidence has proven ultrasound (US) measurement of the optic nerve sheath diameter (ONSD) to be a surrogate for intracranial pressure, a point-of-care procedure that can be conveniently done at bedside $[6,7]$. Increased ONSD has been noted in patients with elevated ICP of various etiologies in ICU, clinic, and emergency departments. Despite the currently available literature, there is no consensus regarding the cut-off of ONSD for elevated ICP. The present meta-analysis aims to determine the ONSD measured in patients with various elevated ICP etiologies under different clinical settings, as well as comparing the value of ONSD between patients with and without elevated ICP.

\section{Materials and methods Literature search}

This meta-analysis complied with the Preferred Reporting Items for Systematic Reviews and Meta-analysis Statement [8]. PubMed, Embase, and Cochrane Library were searched to identify ONSD measured by US for patients with increased ICP from establishment to October 2020. The following keywords were used: "optic nerve sheath diameter", "ultrasound", "intracranial", "pressure", and "hypertension".

\section{Inclusion criteria and exclusion criteria}

The following inclusion criteria were adopted: (a) patients who underwent US measurement of ONSD; (b) patients with elevated ICP; (c) ONSD must be reported in mean and standard deviation on US; (d) confirmation of elevated ICP must be done in another modality other than ultrasound and clinical exam such as CT, MRI, lumbar puncture (LP), and invasive intracranial monitoring. A study was excluded if any of the following criteria were met: (a) non-clinical studies; (b) sample size less than 6; (c) case-reports; (d) pediatric and animal population, and (e) irrelevant studies that did not focus on the topic of using US to measure ONSD of patients with intracranial HTN.

Endnote X8 (Clarivate Analytics, Philadelphia, Pennsylvanian) was used to identify duplicates. Titles, abstracts, and key words were screened, followed by the review of full texts of the remaining studies.

\section{Data collection and statistical analysis}

Baseline characteristics were extracted from each study including author, year of publication, country, study design, sample size, "gold-standard" of increased ICP, optic nerve diameter measured by US, hospital setting, etiology of increased ICP. "Gold-standard" is defined as increased ICP confirmed by CT, MRI, lumbar puncture (LP), or invasive intracranial monitoring. Optic nerve diameter was only included if reported in mean and standard deviation. Two researchers extracted the data from the original studies, and any disagreement was resolved through review and discussion.

Quantitative analysis was performed with Stata 15.1 (STATA Corp., College Station, TX, USA). Meta-analysis was conducted with the -metan function. Heterogeneity was assessed with the $\mathrm{I}^{2}$ statistics. A random-effect model was used for a more conservative estimation due to the quality of included studies. Optic nerve diameters were pooled if reported by original articles. Subgroup analysis was made based on hospital settings, etiology of increased ICP, and "gold-standard" of ICP measurement. Comparison of the increased ICP and normal ICP groups was performed via standard mean difference (SMD) by including comparative studies. Funnel plot and Egger's tests were implemented to assess publication bias.

\section{Results}

\section{Baseline characteristics}

Among the initial 497 unique search results (Fig. 1), a total of 779 patients with elevated ICP among 22 studies were included in the present meta-analysis. Studies were published between 2003 and 2020. Eighteen were comparative $(18 / 22,81.8 \%)$, and four were single-armed study $(4 / 22,18.2 \%)$. Twenty were prospective studies $(20 / 22$, $90.9 \%)$. Studies were performed in USA $(n=3)$, China $(n=3)$, India $(n=3)$, Italy $(n=2)$, Turkey $(n=1)$, Thailand $(n=1)$, Spain $(n=1)$, Saudi Arabia $(n=1)$, Pakistan $(n=1)$, Nigeria $(n=1)$, Iraq $(n=1)$, Finland $(n=1)$, and France $(n=1)$. The brand of US machine implemented by each study is listed in Table 1 . All studies measured ONSD at $3 \mathrm{~mm}$ posterior to the globe, with varying transverse and/or sagittal measurements and repetition times (Table 1).

\section{ONSD measured by ultrasound}

Based on 743 patients from 22 studies with elevated ICP, the overall pooled ONSD measured by ultrasound was $5.82 \mathrm{~mm}$ (95\% CI 5.58-6.06). Based on etiology of increased ICP, patients who had trauma, hydrocephalus, and pseudotumor cerebri had ONSD of 6.12 (95\% CI 5.88-6.35) mm, 5.80 (95\% CI 5.64-5.96) $\mathrm{mm}$, and 6.62 (95\% CI 6.45-6.79) mm, respectively. By hospital settings, US ONSD that were measured in the ICU, ED, clinic, and OR had a diameter of 6.25 (95\% CI 5.92-6.57) mm, 5.72 (95\%CI 5.24-6.19) mm, 5.66 (95\%CI 5.60-5.71) mm, and 5.80 (95\% CI 5.64-5.96) mm, respectively. According to 


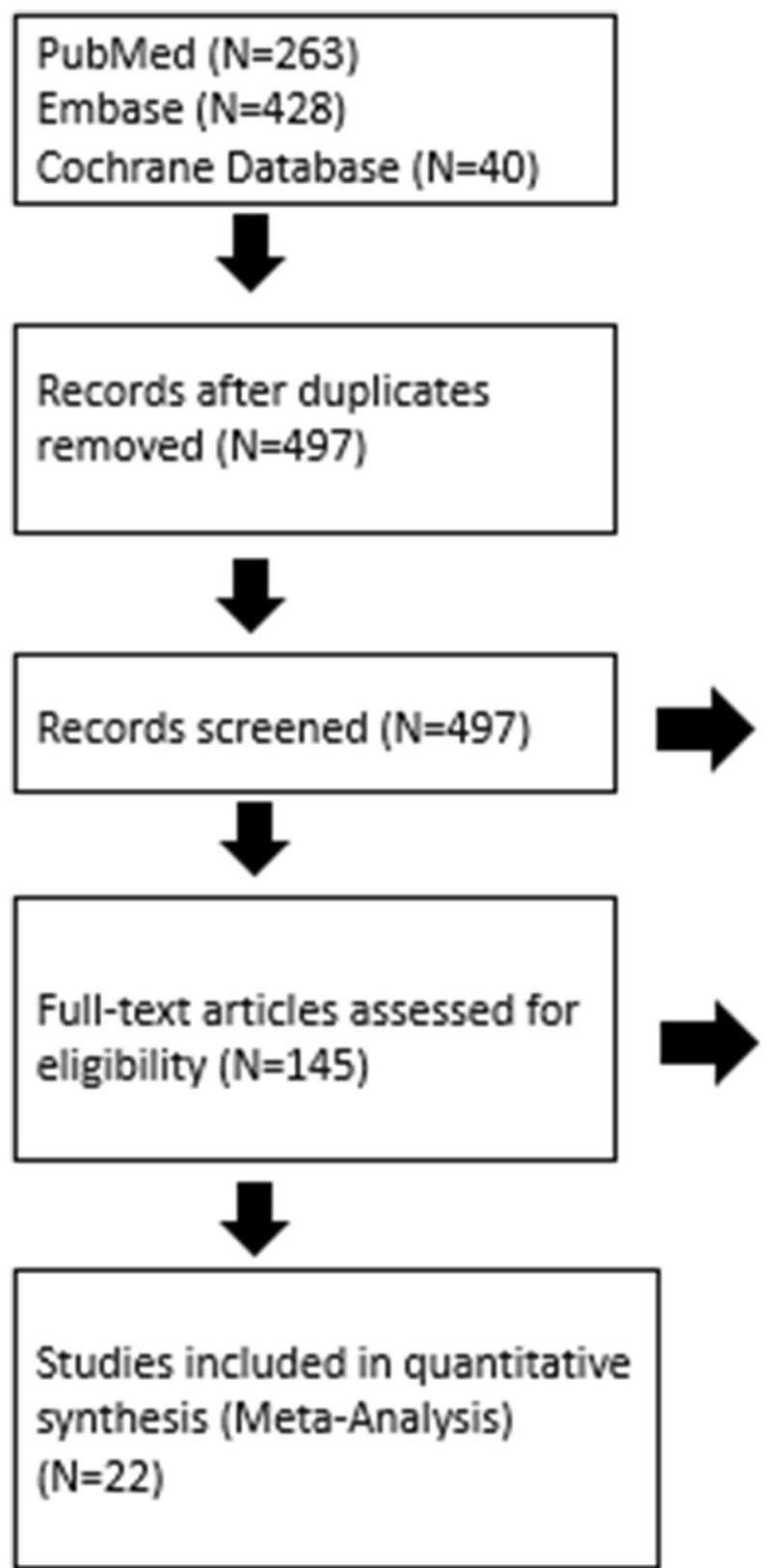

Review \& Meta-analysis $(\mathrm{N}=56)$

Letters \& Commentary $(\mathrm{N}=15)$

Case Report $(\mathrm{N}=42)$

Irrelevant $(\mathrm{N}=62)$

Not full text $(\mathrm{N}=92)$

Animal\&Non-clinical $(\mathrm{N}=20)$

Autopsy/Cadaver $(\mathrm{N}=3)$

Sample Size $<6(\mathrm{~N}=5)$

Pediatric $(\mathrm{N}=57)$

Letters $(\mathrm{N}=2)$

Not Full Text $(\mathrm{N}=1)$

Irrelevant/Not Gold Standard ( $\mathrm{N}=115)$

Pediatric $(\mathrm{N}=2)$

Animal\&Non Clinical $(\mathrm{N}=3)$

Fig. 1 Flow-diagram of manuscript screening and selection

the diagnosis of increased ICP, patients who were diagnosed by CT, MRI, LP, and invasive intracranial monitoring had ONSD on US of 5.67 (95\% CI 5.44-5.91) mm, 5.43 (95\% CI 5.25-5.61) mm, 5.75 (95\% CI 5.09-6.40) $\mathrm{mm}$, and $6.04(95 \%$ CI $5.76-6.32) \mathrm{mm}$, respectively.

\section{ONSD between patients with increased ICP and the normal} cohort

Among 15 comparative studies, 463 and 609 patients had elevated and normal ICP, respectively. The ONSD measured by US was significantly larger among patients with elevated ICP compared to their normal counterparts (5.6 mm vs $4.1 \mathrm{~mm}$, SMD: 2.44 [95\% CI 1.932.95]). Similar findings were seen in each subgroup stratified based on gold-standard diagnosis modalities (CT, LP and invasive monitoring). Funnel plot did not show significant asymmetry (Egger's test: $\mathrm{p}=0.145)$. 
Table 1 Baseline characteristics of included studies

\begin{tabular}{|c|c|c|c|c|c|c|c|c|c|}
\hline Study/year & Region & Design & Sample size & Mean & $\begin{array}{l}\text { Ultrasound } \\
\text { brand }\end{array}$ & $\begin{array}{l}\text { Clinical } \\
\text { setting }\end{array}$ & Diagnosis & Etiology & $\begin{array}{l}\text { Measurement } \\
\text { technique }\end{array}$ \\
\hline $\begin{array}{l}\text { Aduayi } 2015 \\
\text { [9] }\end{array}$ & Nigeria & Prospective & 69 & 5.7 & Mindray DC-6 & Mixed & $\mathrm{CT}$ & Mixed & $\begin{array}{l}3 \text { mm behind } \\
\text { the globe; } 3 \\
\text { times per eye; } \\
\text { averaged }\end{array}$ \\
\hline $\begin{array}{l}\text { Altayar } 2020 \\
\text { [10] }\end{array}$ & Saudi Arabia & Prospective & 28 & 6.6 & Unspecified & $\mathrm{ICU}$ & Inv & Trauma & $\begin{array}{l}3 \text { mm posterior } \\
\text { to the globe } \\
\text { in transverse } \\
\text { and sagittal } \\
\text { planes in both } \\
\text { eyes; average } \\
\text { diameter was } \\
\text { recorded }\end{array}$ \\
\hline $\begin{array}{l}\text { Bhadari } 2019 \\
\text { [11] }\end{array}$ & India & Prospective & 57 & 5.8 & Unspecified & OR & Inv & $\begin{array}{l}\text { Hydrocepha- } \\
\text { lus }\end{array}$ & $\begin{array}{l}3 \mathrm{~mm} \text { behind } \\
\text { the posterior } \\
\text { sclera }\end{array}$ \\
\hline $\begin{array}{l}\text { Blaivas } 2003 \\
\text { [12] }\end{array}$ & USA & Prospective & 14 & 6.27 & Unspecified & ED & $\mathrm{CT}$ & Mixed & $\begin{array}{l}3 \mathrm{~mm} \text { posterior } \\
\text { to the globe } \\
\text { for both eyes } \\
\text { and then aver- } \\
\text { aged. }\end{array}$ \\
\hline $\begin{array}{l}\text { Bäuerle } 2011 \\
\text { [13] }\end{array}$ & Finland & Prospective & 10 & 6.4 & Philips iU22 & Mixed & $L P$ & $\| \mathrm{H}$ & $\begin{array}{l}3 \text { mm behind } \\
\text { the papilla. } \\
\text { Measured } 3 \\
\text { times and } \\
\text { then averaged. }\end{array}$ \\
\hline $\begin{array}{l}\text { Chen } 2019 \\
{[14]}\end{array}$ & China & Prospective & 29 & 4.53 & $\begin{array}{l}\text { Deli- } \\
\text { caMVU-6300 }\end{array}$ & Mixed & LP & Mixed & $\begin{array}{l}3 \text { mm behind } \\
\text { the globe; } \\
\text { averaged two } \\
\text { measure- } \\
\text { ments: one } \\
\text { sagittal and } \\
\text { the other in } \\
\text { the transverse } \\
\text { plane }\end{array}$ \\
\hline $\begin{array}{l}\text { del Saz- } \\
\text { Saucedo } \\
2016 \text { [15] }\end{array}$ & Spain & Prospective & 19 & 6.76 & $\begin{array}{l}\text { Toshiba Apli- } \\
\text { OXG }\end{array}$ & Mixed & $L P$ & $\| \mathrm{H}$ & Transverse plane \\
\hline Du 2020 [16] & China & Prospective & 49 & 5.7 & Sonosite & $\mathrm{ICU}$ & Inv & Trauma & $\begin{array}{l}3 \text { mm behind } \\
\text { the globe; } \\
\text { transverse } \\
\text { plane; aver- } \\
\text { aged two } \\
\text { eyes. }\end{array}$ \\
\hline $\begin{array}{l}\text { Geeraerts } \\
2007[17]\end{array}$ & France & Prospective & 15 & 6.3 & HP Sonos 5500 & $\mathrm{ICU}$ & Inv & Trauma & $\begin{array}{l}3 \mathrm{~mm} \text { behind } \\
\text { the globe; one } \\
\text { sagittal and } \\
\text { one transverse }\end{array}$ \\
\hline Goel 2008 [18] & India & Prospective & 73 & 5.8 & Unspecified & Mixed & $\mathrm{CT}$ & Trauma & $\begin{array}{l}3 \text { mm behind } \\
\text { the globe; } \\
\text { one sagittal } \\
\text { and one } \\
\text { transverse; } \\
\text { averaged }\end{array}$ \\
\hline $\begin{array}{l}\text { Hanafi } 2019 \\
\text { [19] }\end{array}$ & Iran & Prospective & 62 & 6.06 & $\begin{array}{l}\text { SONOSCAPE- } \\
\text { SSI } 6000\end{array}$ & $\mathrm{ED}$ & $C T$ & Trauma & $\begin{array}{l}3 \mathrm{~mm} \text { posterior } \\
\text { to the globe; } 3 \\
\text { times on each } \\
\text { eye in an axial } \\
\text { region; aver- } \\
\text { aged. }\end{array}$ \\
\hline
\end{tabular}


Table 1 (continued)

\begin{tabular}{|c|c|c|c|c|c|c|c|c|c|}
\hline Study/year & Region & Design & Sample size & Mean & $\begin{array}{l}\text { Ultrasound } \\
\text { brand }\end{array}$ & $\begin{array}{l}\text { Clinical } \\
\text { setting }\end{array}$ & Diagnosis & Etiology & $\begin{array}{l}\text { Measurement } \\
\text { technique }\end{array}$ \\
\hline $\begin{array}{l}\text { Kimberly } 2008 \\
\text { [20] }\end{array}$ & USA & Prospective & 8 & 5.4 & $\begin{array}{l}\text { Sonosite } \\
\text { Micromaxx }\end{array}$ & Mixed & $\operatorname{lnv}$ & Mixed & $\begin{array}{l}3 \text { mm posterior } \\
\text { to the orbit; } \\
\text { axial image; } \\
\text { six measure- } \\
\text { ments; aver- } \\
\text { aged. }\end{array}$ \\
\hline $\begin{array}{l}\text { Komut } 2016 \\
\text { [21] }\end{array}$ & Turkey & Prospective & 50 & 5.4 & $\begin{array}{l}\text { Toshiba Aplio } \\
500 \text { Platinum }\end{array}$ & ED & $\mathrm{CT}$ & Mixed & $\begin{array}{l}3 \text { mm proximal } \\
\text { to the optic } \\
\text { disc; in } \\
\text { transverse and } \\
\text { sagittal planes. }\end{array}$ \\
\hline $\begin{array}{l}\text { Mohson } 2019 \\
\text { [22] }\end{array}$ & Iraq & Prospective & 40 & 5.6558 & $\begin{array}{l}\text { Philips } \\
\text { HD11XE }\end{array}$ & Clinic & $L P$ & Mixed & $\begin{array}{l}3 \text { mm posterior } \\
\text { to the globe; } \\
\text { transverse. }\end{array}$ \\
\hline $\begin{array}{l}\text { Moretti } 2009 \\
\text { [23] }\end{array}$ & Italy & Prospective & 19 & 6.2 & $\begin{array}{l}\text { Hitachi EUB } \\
\quad 405\end{array}$ & ICU & Inv & Trauma & $\begin{array}{l}3 \text { mm behind } \\
\text { the globe; } \\
\text { one sagittal } \\
\text { and one trans- } \\
\text { verse. }\end{array}$ \\
\hline Nash 2015 [24] & USA & Prospective & 9 & 5.8 & $\begin{array}{l}\text { SonoSite } \\
\text { M-Turbo }\end{array}$ & Mixed & Inv & Trauma & $\begin{array}{l}3 \text { mm posterior } \\
\text { to the optic } \\
\text { disk; longi- } \\
\text { tudinal and } \\
\text { transverse. }\end{array}$ \\
\hline $\begin{array}{l}\text { Rehman } 2016 \\
\text { [25] }\end{array}$ & Pakistan & $\begin{array}{l}\text { Cross-sec- } \\
\text { tional }\end{array}$ & 13 & 6.61 & $\begin{array}{l}\text { Toshiba Xario } \\
200\end{array}$ & Mixed & $L P$ & $\| \mathrm{H}$ & $\begin{array}{l}3 \mathrm{~mm} \text { behind } \\
\text { the retina; } 3 \\
\text { readings were } \\
\text { averaged. }\end{array}$ \\
\hline $\begin{array}{l}\text { Shirodikar } \\
2014 \text { [26] }\end{array}$ & India & Prospective & 35 & 5.43 & Unspecified & Mixed & MRI & Mixed & $\begin{array}{l}3 \text { mm behind } \\
\text { the globe; } \\
\text { averaging } \\
\text { three readings } \\
\text { from each eye. }\end{array}$ \\
\hline $\begin{array}{l}\text { Tarzamni } 2016 \\
\text { [27] }\end{array}$ & Iran & Prospective & 30 & 5.48 & $\begin{array}{l}\text { Aloka Model } \\
\text { Prosound } \\
3500\end{array}$ & Mixed & $\mathrm{CT}$ & Mixed & $\begin{array}{l}3 \mathrm{~mm} \text { posterior } \\
\text { to the globe; } \\
\text { transverse and } \\
\text { sagittal; aver- } \\
\text { aged. }\end{array}$ \\
\hline $\begin{array}{l}\text { Ussahgiij } 2020 \\
\text { [28] }\end{array}$ & Thailand & Prospective & 29 & 5.3 & $\begin{array}{l}\text { SonoSite } \\
\text { M-Turbo }\end{array}$ & $\mathrm{ED}$ & $\mathrm{CT}$ & Mixed & $3 \mathrm{~mm}$ posterior. \\
\hline $\begin{array}{l}\text { Wang } 2015 \\
\text { [29] }\end{array}$ & China & $\begin{array}{l}\text { Cross-sec- } \\
\text { tional }\end{array}$ & 101 & 4.58 & Philips iU22 & Mixed & $L P$ & Mixed & $\begin{array}{l}3 \text { mm posterior } \\
\text { to the orbit; } \\
\text { transverse } \\
\text { and sagittal; } \\
\text { repeated } \\
\text { twice; aver- } \\
\text { aged }\end{array}$ \\
\hline $\begin{array}{l}\text { Zoerle } 2020 \\
\text { [30] }\end{array}$ & Italy & Prospective & 20 & 6.44 & Phillips iE33 & $\mathrm{ICU}$ & $\operatorname{lnv}$ & Trauma & $\begin{array}{l}3 \text { mm behind } \\
\text { the globe; } \\
\text { transverse } \\
\text { and sagittal; } \\
\text { repeated } \\
\text { twice; aver- } \\
\text { aged }\end{array}$ \\
\hline
\end{tabular}




\section{Discussion}

The use of ultrasound in the hospital setting has increased drastically in recent years due to multiple factors such as advancements of technology, minimal invasiveness, affordability, ease of use, and increased access to providers [31-37]. Ultrasound is a valuable tool due to its ability to identify or rule-out certain pathologies quickly and efficiently [31-34]. As a result, it has been used in combination with gold standard techniques, which are oftentimes more invasive and require extended time.

The gold standard method to measure intracranial pressure (ICP) is intracranial monitoring with an intraventricular catheter, which typically requires an intraparenchymal catheter to be passed through a cranial burr hole into the ventricle. However, this test has multiple downsides even though it can determine the most accurate value [4, 38], including complications such as infection, post-procedural hemorrhage (due to device placement), parenchymal destruction, and misplacement in addition to other factors such as increased time for device placement and requirement for skilled in-house personnel, typically neurosurgeons [4]. Other less invasive tests that can identify increased ICP include radiological means such as CT and MRI, transcranial Doppler, ophthalmoscopy, tympanic displacement, and optic nerve sheath diameter [38]. As a result, these less invasive tests, especially those involving ultrasound, are frequently used as adjuncts or alternatives to more invasive monitoring. Recently, the use of optic nerve ultrasound as a noninvasive, accurate, safe, reproducible, and costeffective tool for ICP via the measurement of optic nerve sheath diameter (ONSD) has been validated, thereby decreasing the potentially detrimental consequences of invasive transcranial measurements [6, 9-30].

The anatomical relationship between the optic nerve and subarachnoid space results in an expansion of the optic nerve sheath in states of increased intracranial pressure $[9,12]$. Thus, optic nerve sheath diameter can provide information regarding ICP. Ultrasound enables a noninvasive measurement to be taken $3 \mathrm{~mm}$ behind the globe, in a retro bulbar position, with a high frequency linear ultrasound probe, which allows for appropriate contrast between the optic nerve and retro bulbar fat to ensure accurate reference points $[9,12,16]$. Normally, three measures for each eye are taken and then averaged. Based on comparative studies, the US-ONSD among patients with elevated ICP was significantly greater than their normal ICP counterparts (Fig. 2A).

Nonetheless, the definitive mean value for ONSD in states of increased ICP has been a point of contention and controversy for many years due lack of meta-analysis and the inability to place an intracranial monitor in all patients where ICP is monitored to correlate this measurements in a more reliable way, though this value approximately lies between 5 and $6 \mathrm{~mm}$ based on prior literature $[6,9,11,16-18,20-24,26,28]$. In order to narrow this range to a more specific value, the present meta-analysis increases the power of the study by pooling available evidence in the literature. According to 22 unique studies over the past 17 years, the overall pooled ONSD measured by ultrasound was found to be 5.82 (95\% CI 5.58-6.06) $\mathrm{mm}$, consistent with previously reported MRI measurements (5.81-5.82 mm) [31, 32]. Subtle variations in mean values may be attributed to study site variation in diagnostic control (i.e., CT vs. MRI vs. LP vs. ICP monitor), patient variation such as anatomical differences or severity of illness (i.e., ICU status, etc.), and user variation such as ultrasound probe placement, reference points used for measurements, and the inter equipment variation related with ultrasound devices themselves (i.e., probe frequency, image quality, etc.). Widespread training in this practice is expected to increase precision and accuracy of measurements, and thus sensitivity and specificity of the exam findings.

Due to the easy accessibility of US compared to other imaging modality such as CT and MRI, it can be implemented by physicians in a variety of clinical settings, such as the ED, OR, ICU, clinic, wards, etc. (Table 1). US-ONSD measured in ICU patients demonstrated the largest value 6.25 (95\% CI 5.92-6.57) mm (Fig. 3), reflecting the critically ill nature of this patient population and higher ICP requiring ICU care. Because the use of US is operator-dependent, the accuracy and precision of USONSD can be influenced by type of clinical setting where measurement takes place. For instance, measuring USONSD in a busy ED can be more technically challenging compared to in a controlled environment such as OR or ICU where patients are sedated. Further matched-comparative studies are warranted to compare its use in different clinical settings.

Previous studies indicated a strong correlation between increased ONSD and radiologic findings with $\mathrm{CT}$ and MRI [6, 9, 39, 40]. Patients diagnosed with increased ICP by CT or MRI had lower ONSDs on ultrasound (5.67 mm; 95\% CI 5.44-5.91 $\mathrm{mm}$ and $5.43 \mathrm{~mm}$; 95\% CI $5.25-5.61 \mathrm{~mm})$ than patients diagnosed with invasive ICP monitoring (6.04 mm; 95\% CI 5.76-6.32 mm). Brain Trauma Foundation recommends considering invasive ICP monitoring under the setting of severe head injury [41]; the longer pooled ONSD of these patients in the present meta-analysis might be related to the severity of increased ICP prompted invasive monitoring.

The present meta-analysis also found variations of ONSD among different etiologies of intracranial hypertension (Fig. 4), though there were only three study dedicated to IIT and one focusing on hydrocephalus. 

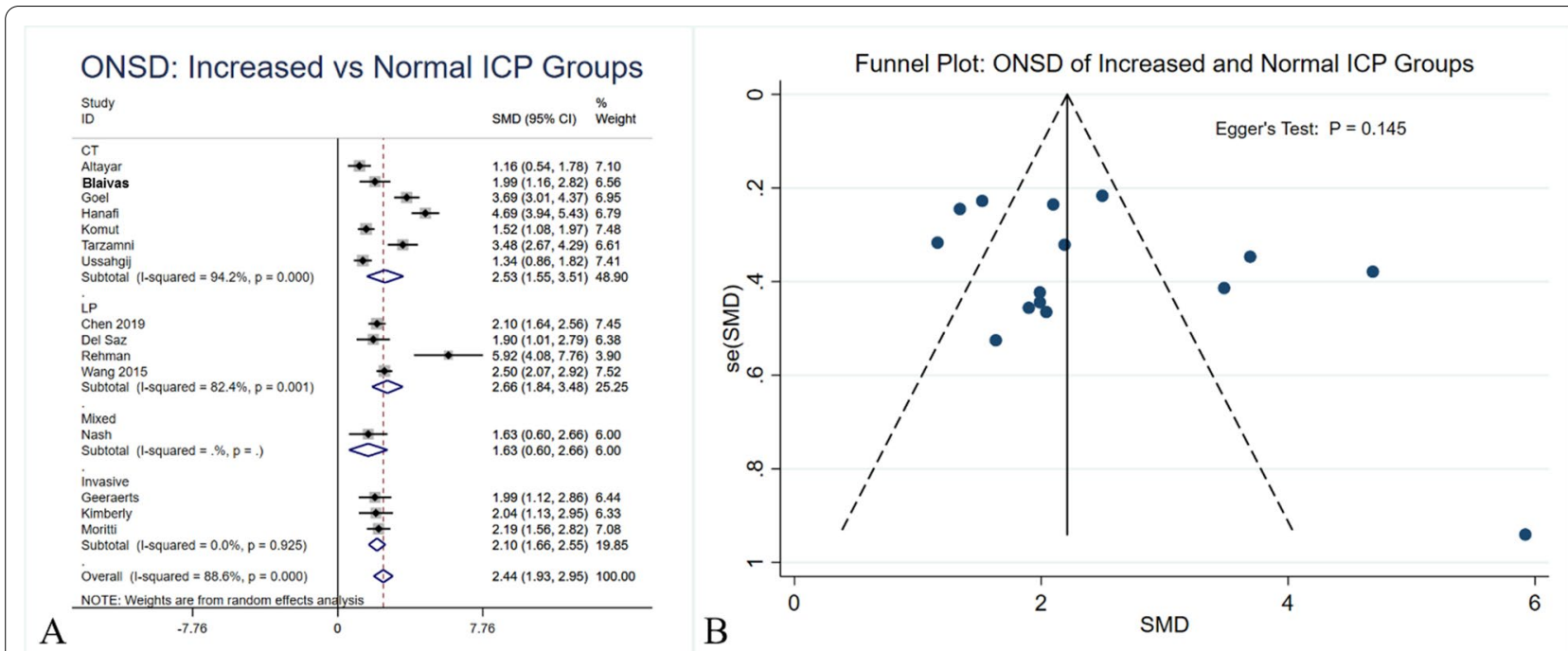

Fig. 2 Optic nerve sheath diameter (ONSD) measured by ultrasound (US) between patients with elevated intracranial pressure (ICP) and normal cohort (A). Funnel plot and Egger's test evaluating publication bias (B)

Compared to hydrocephalus, values for traumatic etiologies were greater than hydrocephalus $(6.12[95 \% \mathrm{CI}$ 5.88-6.35] vs 5.8 [95\%CI 5.64-5.96] $\mathrm{mm}$ ), which may be explained by the rapid increase in ICP due to mass effect from head injury. However, the pooled pressure of idiopathic intracranial hypertension was the highest (6.62 [95\%CI 6.45-6.79)] $\mathrm{mm}$ ), which is possibly due to chronic change. Such observation could be affected by the etiology of the disease. Based on the modified Dandy criteria, papilledema is one criterion of diagnosing idiopathic intracranial hypertension [42]. Because papilledema is optic disc edema resulted from elevated ICP transmitted through optic nerve sheath [43], increase of ONSD should takes precedence prior to the development of papilledema. Because of under powering of the number of included studies, these speculation warrants further research (Fig. 5).

Fifteen studies compared the ONSD between patients with increased ICP and a normal cohort (Fig. 2). The ONSD measured by US was significantly larger among patients with elevated ICP compared to their normal counterparts (5.6 mm vs $4.1 \mathrm{~mm}$, SMD: 2.44 [95\% CI 1.93-2.95]).

The present study should be interpreted with several caveats. Despite most studies being prospective in nature, baseline patient characteristics can be heterogeneous such as the etiology of increased ICP and clinical settings where US-ONSD measurement was taken place. Subgroup analyses were performed and showed variations in terms of the pooled value in each condition. Nonetheless, the majority of studies were reported
ONSD among a mixed population. Future study should report outcomes stratified based on these variables to determine the mean value for elevated ICP in each clinical scenario. Further, the present meta-analysis did not analyze the sensitivity and specificity of the pooled US-ONSD value. Such analysis requires each individual study reporting sensitivity and specificity in the original article, but the criteria of US-ONSD for elevated ICP vary among different authors. A number of studies for the ONSD evaluation used the median values rather than the mean value. Although in our analysis we used all the values relevant in the literature to obtained mean values, this could be a potential confounder when trying to establish an accurate value. ONSD values are usually represented as the average of measurements between the eyes. Normally, three measures for each eye are taken and then averaged. However, some studies used only two measures per eye, and some others used one transverse measurement and one on vertical plane per eye (averaged). Furthermore, some studies have suggested an "internal" ONSD (ONSDi) and an "external" ONSD (ONSDe). The two measurements can differ. These factors can produce differences of measurements and potential bias may be created.

Even if there are several limitations about the use of a unique cut-off value of ONSD for detecting elevated ICP, this update may help to clarify which is the value that could be considered as marker of intracranial hypertension.

Thus, the aim of the present study was to pool the US-ONSD using available studies to determine a mean 


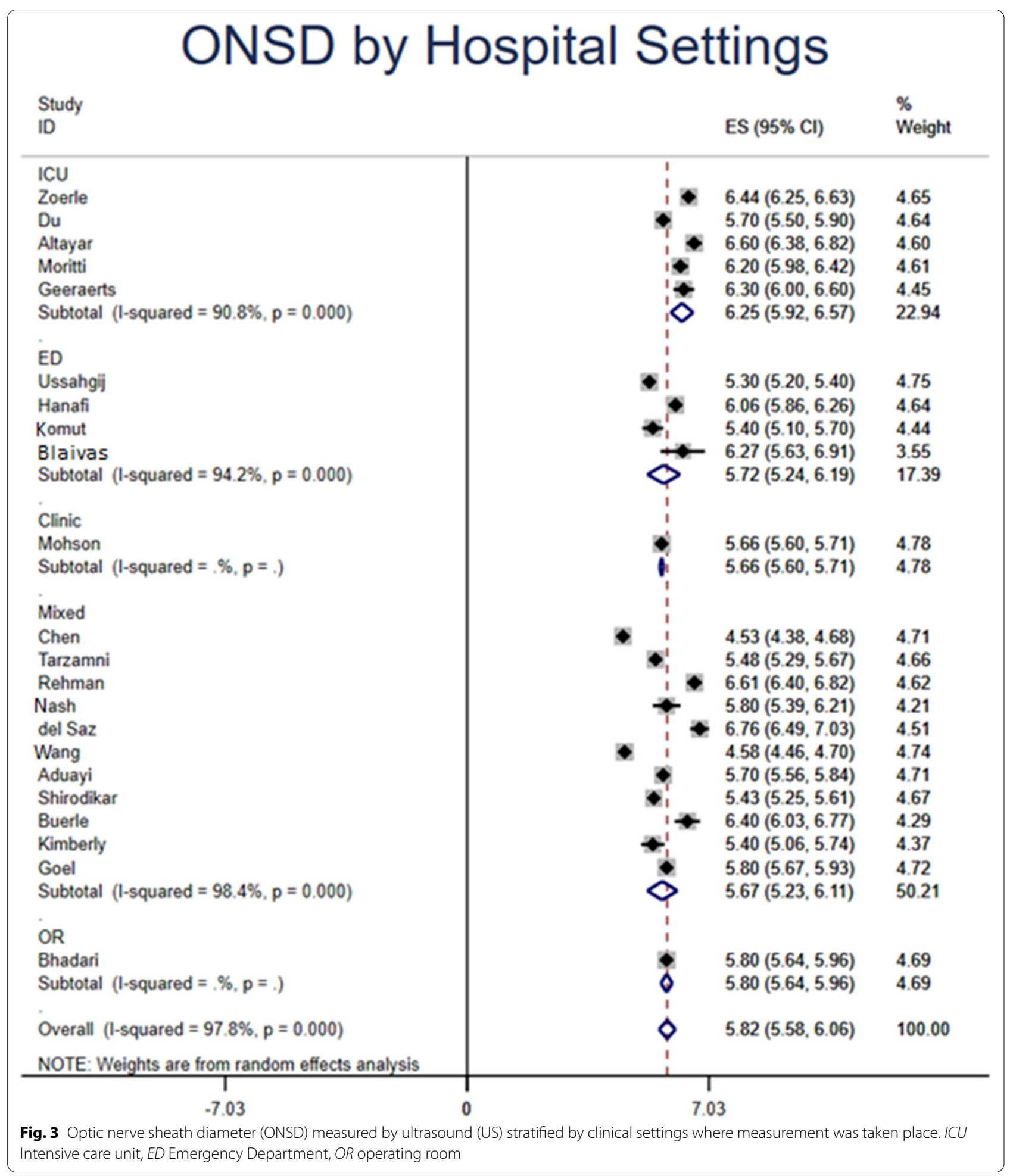

value that can be used as a reference for future study to determine its specificity and sensitivity in real-world clinical practice.

\section{Conclusions}

Based on available evidence, the mean value of the ONSD among patients diagnosed with increased ICP 


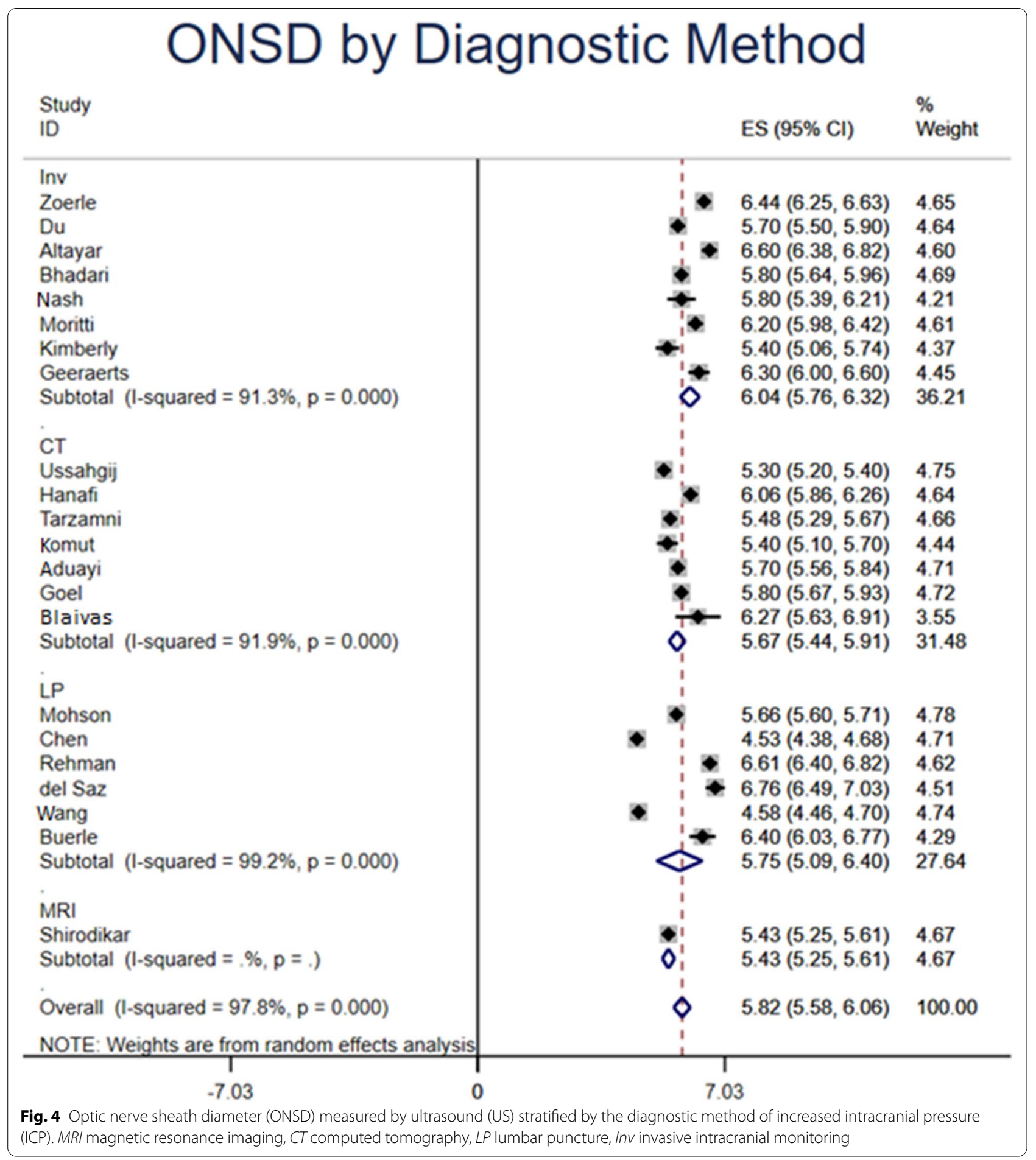

was $5.82 \mathrm{~mm}$ (95\% CI 5.58-6.06 mm). Variations were observed based on etiology of intracranial hypertension, clinical settings where ONSD was measured, and standards for diagnosing intracranial hypertension. The US-ONSD among patients with elevated ICP was significantly higher than the normal control. Although a cut-off value is not clearly determined these mean values can be implemented to evaluate the sensitivity and specificity of US-ONSD in diagnosing intracranial hypertension in future studies. Larger, stratified, 


\section{ONSD by Etiology}

Study

ID

ES $(95 \% \mathrm{Cl}) \quad$ Weight

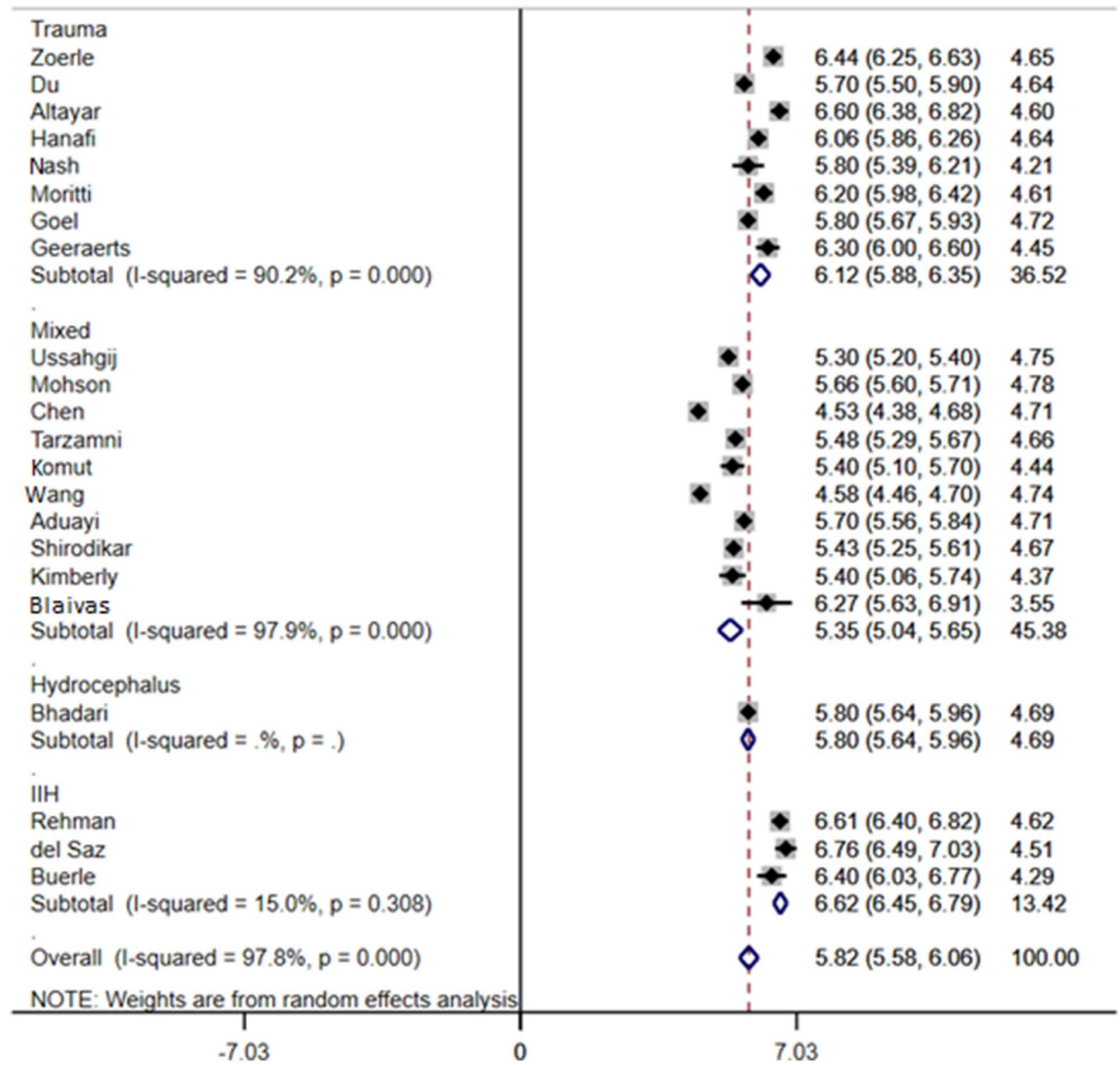

Fig. 5 Optic nerve sheath diameter (ONSD) measured by ultrasound (US) stratified by etiology of elevated intracranial pressure

prospective studies are warranted to determine its value in each clinical setting.

\section{Acknowledgements}

Not applicable.

\section{Authors' contributions}

LM: manuscript writing, review and final edition. QY: data collection and analysis. SJB: manuscript writing and edition. SS: Data analysis. RJR: manuscript edition. MM: main hypothesis, manuscript final review and edition, advisory input. All authors read and approved the final manuscript.

Funding

No funding was obtained for this research.

Availability of data and materials

All data are available from the authors upon request. 


\section{Declaration}

\section{Ethics approval and consent to participate}

Not applicable.

\section{Consent for publication}

All authors consent for publication. All authors of the manuscript have read and agreed to its content.The manuscript is original, has not already been published, and is not currently under consideration by another journal.

\section{Competing interests}

The authors declare no competing interests.

\section{Author details}

${ }^{1}$ Department of General Surgery, Cleveland Clinic Florida, 2950 Cleveland Clinic Blvd, Weston, FL, USA. ${ }^{2}$ School of Medicine, Georgetown University, Washington D.C, USA. ${ }^{3}$ Department of Ultrasound and Vascular Doppler, Hospital de Emergencias "Dr. Clemente Alvarez", Av. Pellegrini 3205, Rosario, Santa Fe, Argentina.

Received: 4 March 2021 Accepted: 22 June 2021

Published online: 02 July 2021

\section{References}

1. Canac N, Jalaleddini K, Thorpe SG, Thibeault CM, Hamilton RB (2020) pathophysiology of intracranial hypertension and noninvasive intracranial pressure monitoring. Fluids Barriers CNS 17(1):1-21

2. Farahvar A, Gerber LM, Chiu Y-L, Carney N, Härtl R, Ghajar J (2012) Increased mortality in patients with severe traumatic brain injury treated without intracranial pressure monitoring. J Neurosurg 117(4):729-734

3. Han J, Yang S, Zhang C, Zhao M, Li A (2016) Impact of intracranial pressure monitoring on prognosis of patients with severe traumatic brain injury: a PRISMA systematic review and meta-analysis. Medicine 95:7

4. Tavakoli S, Peitz G, Ares W, Hafeez S, Grandhi R (2017) Complications of invasive intracranial pressure monitoring devices in neurocritical care. Neurosurg Focus 43(5):E6

5. Kayhanian S, Young AM, Piper RJ et al (2018) Radiological correlates of raised intracranial pressure in children: a review. Front Pediatr 6:32

6. Dubourg J, Javouhey E, Geeraerts T, Messerer M, Kassai B (2011) Ultrasonography of optic nerve sheath diameter for detection of raised intracranial pressure: a systematic review and meta-analysis. Intens Care Med 37(7):1059-1068

7. Montorfano L, Giambartolomei G, Funes DR, Lo Menzo E, Dip F, White KP, Rosenthal RJ (2020) The Cushing reflex and the vasopressin-mediated hemodynamic response to increased intracranial pressure during acute elevations in intraabdominal pressure. Surgery 167(2):478-483

8. Moher D, Shamseer L, Clarke M et al (2015) Preferred reporting items for systematic review and meta-analysis protocols (PRISMA-P) 2015 statement. Syst Control Found Appl 4(1):1

9. Aduayi OS, Asaleye CM, Adetiloye VA, Komolafe EO, Aduayi VA (2015) Optic nerve sonography: a noninvasive means of detecting raised intracranial pressure in a resource-limited setting. J Neurosci Rural Pract 6(4):563

10. Altayar AS, Abouelela AZ, Abdelshafey EE et al (2020) Optic nerve sheath diameter by ultrasound is a good screening tool for high intracranial pressure in traumatic brain injury. Irish J Med Sci 8:254

11. Bhandari D, Udupi Bidkar P, Adinarayanan S, Narmadhalakshmi K, Srinivasan S (2019) Measurement of changes in optic nerve sheath diamete using ultrasound and computed tomography scan before and after the ventriculoperitoneal shunt surgery in patients with hydrocephalus-A prospective observational trial. Br J Neurosurg 33(2):125-130

12. Blaivas $M$, Theodoro D, Sierzenski PR (2003) Elevated intracranial pressure detected by bedside emergency ultrasonography of the optic nerve sheath. Acad Emerg Med 10(4):376-381

13. Bäuerle J, Nedelmann M (2011) Sonographic assessment of the optic nerve sheath in idiopathic intracranial hypertension. J Neurol 258(11):2014-2019

14. Chen LM, Wang $\sqcup$, Shi L, Chen HX, Jiang XH, Chen QQ, Xing YQ (2019) Reliability of assessing non-severe elevation of intracranial pressure using optic nerve sheath diameter and transcranial Doppler parameters. Front Neurol 22(10):1091

15. del Saz-Saucedo P, Redondo-González O, Mateu-Mateu Á, Huertas-Arroyo R, García-Ruiz R, Botia-Paniagua E (2016) Sonographic assessment of the optic nerve sheath diameter in the diagnosis of idiopathic intracranial hypertension. J Neurol Sci 361:122-127

16. Du J, Deng Y, Li H et al (2020) Ratio of optic nerve sheath diameter to eyeball transverse diameter by ultrasound can predict intracranial hypertension in traumatic brain injury patients: a prospective study. Neurocrit Care 32(2):478-485

17. Geeraerts T, Launey Y, Martin L et al (2007) Ultrasonography of the optic nerve sheath may be useful for detecting raised intracranial pressure after severe brain injury. Intensive Care Med 33(10):1704-1711

18. Goel RS, Goyal NK, Dharap SB, Kumar M, Gore MA (2008) Utility of optic nerve ultrasonography in head injury. Injury 39(5):519-524

19. Hanafi MG, Verki MM, Parei SN (2019) Ultrasonic assessment of optic nerve sheath to detect increased intracranial pressure. J Med Ultrasound 27(2):69

20. Kimberly HH, Shah S, Marill K, Noble V (2008) Correlation of optic nerve sheath diameter with direct measurement of intracranial pressure. Acad Emerg Med 15(2):201-204

21. Komut E, Kozaci N, Sönmez BM, et al. Bedside sonographic measurement of optic nerve sheath diameter as a predictor of intracranial pressure in ED. Am J Emerg Med. 2016;34(6):963-7.

22. Mohson Kl, Auday N (2019) Role of orbital ultrasound in the assessment of clinically detected papilledema. J Med Ultrasound 27(3):135

23. Moretti R, Pizzi B (2009) Optic nerve ultrasound for detection of intracranial hypertension in intracranial hemorrhage patients: confirmation of previous findings in a different patient population. J Neurosurg Anesthesiol 21(1):16-20

24. Nash JE, O'Rourke C, Moorman ML (2016) Transocular ultrasound measurement of the optic nerve sheath diameter can identify elevated intracranial pressure in trauma patients. Trauma 18(1):28-34

25. Rehman H, Khan MS, Nafees M, Rehman AU, Habib A (2016) Optic nerve sheath diameter on sonography in idiopathic intracranial hypertension versus normal. JCPSP 26(9):758-760

26. Shirodkar CG, Rao SM, Mutkule DP, Harde YR, Venkategowda PM, Mahesh MU (2014) Optic nerve sheath diameter as a marker for evaluation and prognostication of intracranial pressure in Indian patients: an observational study. Ind J Critic Care Med 18(11):728

27. Tarzamni MK, Derakhshan B, Meshkini A et al (2016) The diagnostic performance of ultrasonographic optic nerve sheath diameter and color Doppler indices of the ophthalmic arteries in detecting elevated intracranial pressure. Clin Neurol Neurosurg 141:82-88

28. Ussahgij W, Toonpirom W, Munkong W, Lenghong K, Apiratwarakul K (2020) Optic nerve sheath diameter cutoff point for detection of increased intracranial pressure in the emergency department. J Med Sci 8:62-65

29. Wang L, Feng L, Yao Y, Wang $Y$, Chen $Y$, Feng J, Xing Y (2015) Optimal optic nerve sheath diameter threshold for the identification of elevated opening pressure on lumbar puncture in a Chinese population. PLOS ONE 10(2):e0117939

30. Zoerle T, Caccioppola A, D'Angelo E et al (2020) Optic nerve sheath diameter is not related to intracranial pressure in subarachnoid hemorrhage patients. Neurocritic Care. 14:1-8

31. Liao SF, Chen PJ, Chaou CH, Lee CH (2018) Top-cited publications on point-of-care ultrasound: The evolution of research trends. Am J Emerg Med 36(8):1429-1438

32. Kendall JL, Hoffenberg SR, Smith RS (2007) History of emergency and critical care ultrasound: the evolution of a new imaging paradigm. Crit Care Med 35(5 Suppl):S126-S130

33. Carson PL, Fenster A (2009) Anniversary paper: evolution of ultrasound physics and the role of medical physicists and the AAPM and its journal in that evolution. Med Phys 36(2):411-428

34. Montoya J, Stawicki SP, Evans DC, Bahner DP, Sparks S, Sharpe RP, Cipolla J (2016) From FAST to E-FAST: an overview of the evolution of ultrasound-based traumatic injury assessment. Eur J Trauma Emerg Surg 42(2):119-126

35. Cosgrove DO (2017) Evolution of ultrasonography since the 1970s. Ultrasound Med Biol 43(11):2741-2742. https://doi.org/10.1016/j.ultrasmedb io.2017.06.015 
36. Goldberg BB, Gramiak R, Freimanis AK (1993) Early history of diagnostic ultrasound: the role of American radiologists. Am J Roentgenol 160(1):189-194. https://doi.org/10.2214/ajr.160.1.8416623

37. Newman PG, Rozycki GS (1998) The history of ultrasound. Surg Clin North Am 78(2):179-195. https://doi.org/10.1016/s0039-6109(05)70308-x

38. Nag DS, Sahu S, Swain A, Kant S (2019) Intracranial pressure monitoring: gold standard and recent innovations. World J Clin Cases 7(13):1535-1553

39. Geeraerts T, Newcombe VF, Coles JP et al (2008) Use of T2-weighted magnetic resonance imaging of the optic nerve sheath to detect raised intracranial pressure. Crit Care 12(5):1-7

40. Abdelrahman AS, Barakat MM (2020) MRI measurement of optic nerve sheath diameter using 3D driven equilibrium sequence as a non-invasive tool for the diagnosis of idiopathic intracranial hypertension. Egypt J Radiol Nuclear Med 51(1):24

41. Brain TF (2007) Guidelines for the management of severe traumatic brain injury. X. Brain oxygen monitoring and thresholds. J Neurotrauma 24:S65

42. Friedman DI, Jacobson DM (2002) Diagnostic criteria for idiopathic intracranial hypertension. Neurology 59(10):1492-1495

43. Rigi M, Almarzouqi SJ, Morgan ML, Lee AG (2015) Papilledema: epidemiology, etiology, and clinical management. Eye and brain 7:47

\section{Publisher's Note}

Springer Nature remains neutral with regard to jurisdictional claims in published maps and institutional affiliations.

\section{Submit your manuscript to a SpringerOpen ${ }^{\circ}$ journal and benefit from:}

- Convenient online submission

- Rigorous peer review

- Open access: articles freely available online

- High visibility within the field

- Retaining the copyright to your article

Submit your next manuscript at springeropen.com 